\title{
3D Morphological Study of the Indian Arthritic Knee: Comparison with Other Ethnic Groups and Conformity of Current TKA Implant*
}

\author{
Darshan S. Shah ${ }^{1}$, Rupesh Ghyar ${ }^{1}$, Bhallamudi Ravi ${ }^{1}$, Vijay Shetty ${ }^{2}$ \\ ${ }^{1}$ Department of Mechanical Engineering, Indian Institute of Technology Bombay, Mumbai, India; ${ }^{2}$ Hiranandani Orthopaedic Medical \\ Education, Dr. LH Hiranandani Hospital, Mumbai, India. \\ Email: dssiitb@gmail.com
}

Received October $5^{\text {th }}, 2013$; revised November $5^{\text {th }}, 2013$; accepted November $12^{\text {th }}, 2013$

Copyright (c) 2013 Darshan S. Shah et al. This is an open access article distributed under the Creative Commons Attribution License, which permits unrestricted use, distribution, and reproduction in any medium, provided the original work is properly cited.

\begin{abstract}
Background: Studies have shown that there are striking variations in knee morphology between Asian and Western population. However, most of the existing total knee arthroplasty (TKA) implants are designed to suit the anatomy of Western population. Our study investigated anthropometry of Indian arthritic knees and compared them to international ethnic groups. Methods: Computed tomography was used to create 3D knee models and obtain anthropometric data of distal femur and proximal tibia of Indian arthritic knees. Femoral measurements included mediolateral length, medial and lateral anteroposterior length, medial and lateral condylar width and aspect ratio. Tibial measurements included mediolateral length, medial, lateral and central anteroposterior length and aspect ratio. A preoperative virtual implantation using Western TKA implants was carried out to visualize anatomical conformity. Results: Statistical analysis results showed that Indian males had significantly larger femoral and tibial mediolateral and anteroposterior width than Indian females; however, femoral and tibial aspect ratio was similar for both. In case of females, significant difference was observed between medial and lateral condylar widths. When compared to knee anthropometry of other ethnic groups, femoral and tibial aspect ratio of Indian knees was found to be similar to the Asian population and different from the Western population. The virtual implantation showed overhang of the femoral component in both lateral and medial regions. Conclusion: Morphological mismatch between Western and Indian knees established the fact that Western implants have drawbacks when implanted in Indian patients. The study also provided a basis for designing gender-specific TKA implants for the Indian population.
\end{abstract}

Keywords: Knee Morphology; Total Knee Arthroplasty; Anatomical Conformity; Ethnic Groups

\section{Introduction}

The successful outcome about long life of a total knee arthroplasty (TKA) implant depends on optimum bone resection and maximum coverage of the resected cortical bone $[1,2]$. These factors rely heavily on the size matching of the implant with the resected knee. Commercially available TKA implants do not cater to racial anthropometric differences as suggested by some recent studies [3-5]. Most of these implants are designed according to the anthropometric data of the Western population. Studies have shown that the smaller build and stature of the Asian-Pacific population gives rise to TKA component

${ }^{*}$ Conflict of interest: The authors have declared that there is no conflict of interest associated with this study. mismatch [6]. Since there is a shortage of data on the distal femur and proximal tibia in this population, implants designed for knees of the Western population are currently being used without modifications for the subject ethnic group [7]. Research on TKA mismatching has led to the conclusion that people in Asia Pacific should have special designs of TKA implants. However, whether there are striking variations in knee anthropometry between the Asian and Western population remains unclear. With the increase in the use of TKA in Asia Pacific regions [8], it has become essential to analyze the morphological differences of the knee observed across various ethnic groups to improve the performance of TKA. The aim of the present study was to investigate the anthropometry of the Indian knees using three dimen- 
sional knee models and evaluate them morphologically against other ethnic groups. We hypothesize that there is a distinct difference in size and shape between the Indian knees and Western knees leading to size mismatch of Western TKA implants in Indian patients.

\section{Materials and Methods}

\subsection{Subjects}

50 knees from living subjects were analyzed in this study. The knee joint data of the subjects, including 10 males and 40 females, was collected preoperatively using CT imaging. These subjects were undergoing TKA for bilateral primary osteoarthritis. Patients having other periarticular pathologies such as tumours, rheumatoid arthritis and post-traumatic fracture were excluded from this study. Since both knees of all patients were affected by osteoarthritis, both left and right knees were included in the database.

\subsection{CT Scan Technique}

For all patients, CT scan of the knee was obtained using a helical CT scanner $(130 \mathrm{kV}, 53 \mathrm{~mA}$; Samsung healthcare). The patients were informed about the procedure and written approval for the statistical study was taken. During the scan, the subject was supine with his or her knee in a relaxed and extended position. This scanning procedure was performed to acquire CT slices of thickness $0.5 \mathrm{~mm}$ with a resolution of $512 \times 512$ pixels. The raw data obtained from the scans was copied in DICOM file format which was then exported to medical modeling software (Mimics 10.1, Materialise, Belgium). The images were segmented to construct $3 \mathrm{D}$ bone models of the knee, including the femur and the tibia. This approach is similar to those reported in literature [9]. The 3D models were exported to CAD modeling software (SolidWorks, 2008, Dassault Sys., USA) to perform measurements.

\subsection{Measurements}

Measurements on the distal femur were taken in the plane perpendicular to the femoral axis (Figure 1(a)). The mediolateral and anteroposterior dimensions of the femur were then measured by fitting a rectangular bounding box to the distal femur [10]. A line tangent to posterior aspect of both the condyles, posterior condylar tangent (PCT), was constructed. Two lines perpendicular to PCT and passing through the medial and lateral extremities of the femur were constructed to measure the mediolateral length (fML). Two lines parallel to PCT and passing through anterior extremities of medial and lateral condyles were constructed to measure the medial and lateral anteroposterior lengths (fMAP and fLAP). Lines parallel to PCT and passing through the extremities of the posterior aspect of the medial and lateral condyles were constructed to measure the condylar widths (fMCW and fLCW). The femoral anteroposterior length (fAP) was defined as the maximum of the medial and lateral anteroposterior lengths (fMAP and fLAP). The femoral aspect ratio (fR) was defined as the ratio of mediolateral length to the anteroposterior length (fML/fAP).

Measurements on the proximal tibia were taken in the plane perpendicular to the tibial axis (Figure 1(b)). A line parallel to the PCT and tangent to the anterior extremity of the tibial plateau, anterior tangent (AT), was constructed. Care was taken to avoid the anterior tibial tuberosity as an anterior extremity [11]. Two lines perpendicular to AT and passing through the medial and lateral extremities of the tibia were constructed to measure the mediolateral length (tML). Two additional lines parallel to AT and passing through posterior extremities of medial and lateral plateaux were constructed to measure the medial and lateral anteroposterior lengths (tMAP and tLAP). A line perpendicular to AT and passing through the midpoint of the tML dimension was constructed to

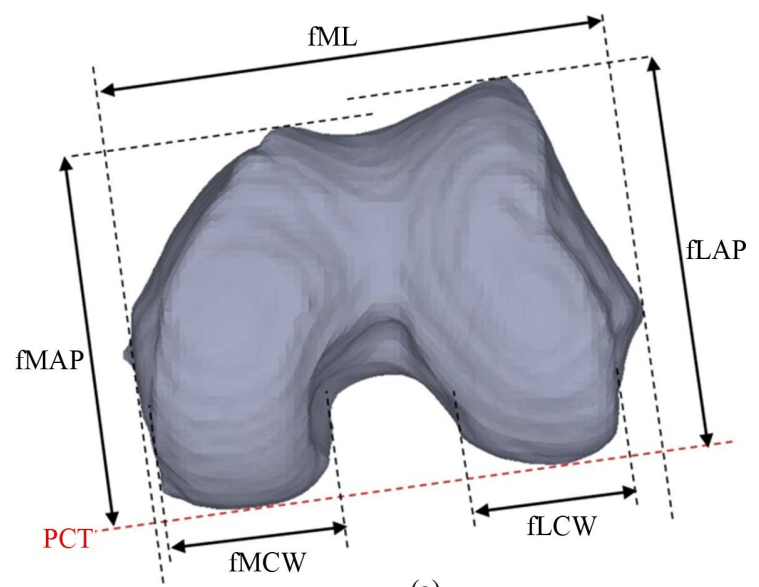

(a)

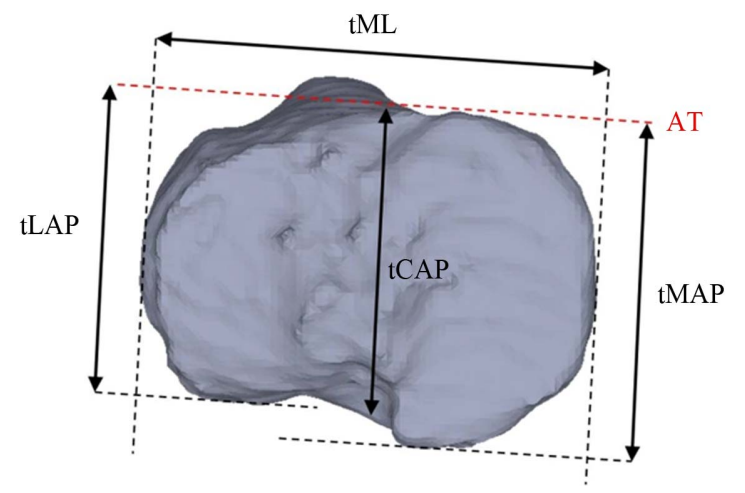

(b)

Figure 1. Measurements performed on 3D bone models; (a) distal femur (b) proximal tibia. 
to measure the tibial central anteroposterior length (tCAP). The tibial anteroposterior length (tAP) was defined as the maximum of the medial and lateral anteroposterior lengths (tMAP and tLAP). The tibial aspect ratio (tR) was defined as the ratio of mediolateral length to the central anteroposterior length (tML/tCAP).

\subsection{Virtual Implantation of Existing Western Prosthesis}

A preoperative virtual implantation was carried out in a 3D CAD environment to visualize anatomical conformity. The 3D model of a femoral component of the Western implant was fitted on a 3D bone model of an Indian femur. The distal plane was constructed perpendicular to mechanical axis and passing from distal extremity of the femoral condyle. The model was resected with a distal cut parallel to distal plane and $9.5 \mathrm{~mm}$ from the distal extremity. Mediolateral distance, parallel to transepicondylar axis, of the resected bone was measured in this plane. A femoral component was selected and bone was resected according to the implant selection guide of the implant manufacturer. The overall alignment and fit of the component was observed.

\subsection{Statistical Analysis}

In the statistical analysis, best-fit lines were calculated with use of least squares regression method. The data was summarized as the mean and standard deviation (mean $\pm \mathrm{SD}$ ). Data analysis of the Indian knees was performed by using the Student t-test. Since anthropometric measurements of the knees of other ethnic groups were retrieved from literature, the data was obtained only in the form of mean $\pm \mathrm{SD}$. Hence, Welch's t-test was used to compare this data with our data of the Indian population. Values for $\mathrm{p}<0.05$ were regarded as statistically significant.

\section{Results}

The average age for males (71.5 \pm 8.1 years, range 64 79 years) was greater than the average age of females $(66.5 \pm 7.7$ years, range $52-80$ years $)(p=0.101)$.

\subsection{Data Analysis of Indian Knee}

The average femoral mediolateral length (fML) was 79.9 $\pm 4.7 \mathrm{~mm}$ and average femoral anteroposterior length (fAP) was $64.6 \pm 4.9 \mathrm{~mm}$ (Table 1). The average medial and lateral anteroposterior length (fMAP and fLAP) was $62.3 \pm 5.1 \mathrm{~mm}$ and $64.3 \pm 4.9 \mathrm{~mm}$. The average femoral aspect ratio was $1.24 \pm 0.06$. Males had larger values of fML, fLAP, fMAP and fAP as compared to females ( $\mathrm{p}<$ 0.01). A positive correlation was observed between fAP
Table 1. Summary of femoral measurements_-Indian knees.

\begin{tabular}{ccccc}
\hline Parameters & Combined & Male & Female & $\mathbf{p}^{\mathbf{a}}$ \\
\hline $\begin{array}{c}\text { Mediolateral (fML) } \\
\text { Medial Antero-Posterior } \\
\text { (fMAP) }\end{array}$ & $79.9 \pm 4.7$ & $83.6 \pm 2.6$ & $76.3 \pm 3.8$ & $<0.01$ \\
$\begin{array}{c}\text { Lateral Antero-Posterior } \\
\text { (fLAP) }\end{array}$ & $64.3 \pm 4.9$ & $67.2 \pm 2.9$ & $61.4 \pm 4.6$ & $<0.01$ \\
$\begin{array}{c}\text { Anteroposterior (fAP) } \\
\text { Aspect Ratio (fR) }\end{array}$ & $64.6 \pm 4.9$ & $67.2 \pm 2.9$ & $62.1 \pm 4.9$ & $<0.01$ \\
$\begin{array}{c}\text { Medial Condylar Width } \\
\text { (fMCW) }\end{array}$ & $31.9 \pm 3.7$ & $33.1 \pm 2.9$ & $30.7 \pm 3.7$ & 0.040 \\
$\begin{array}{c}\text { Lateral Condylar Width } \\
\text { (fLCW) }\end{array}$ & $29.5 \pm 3.7$ & $32.2 \pm 2.4$ & $26.7 \pm 3.1$ & $<0.01$ \\
$\begin{array}{c}\text { Condylar Ratio } \\
\text { (fMCW/fLCW) }\end{array}$ & $1.09 \pm 0.09$ & $1.03 \pm 0.04$ & $1.15 \pm 0.08$ & $<0.01$ \\
\hline
\end{tabular}

${ }^{\mathrm{a}}$ The $\mathrm{p}$-values are calculated for comparison across genders.

and fML for both males and females (Figure 2(a)). In case of the femoral aspect ratio (fR), no statistically significant difference was found between males and females $(\mathrm{p}=$ 0.293). The medial condylar width (fMCW) was larger than lateral condylar width (fLCW) in case of females (p $<0.01$ ); however, there was no statistically significant difference between fMCW and fLCW for males ( $=0.434)$. A positive correlation was observed between fMCW and fLCW for both males and females (Figure 2(c)).

The average tibial mediolateral length (tML) was 76.6 $\pm 4.9 \mathrm{~mm}$ and average tibial anteroposterior length was $55.4 \pm 4.6 \mathrm{~mm}$ (Table 2). The average medial, lateral and central anteroposterior length (tMAP, tLAP and tCAP) was $53.3 \pm 4.9 \mathrm{~mm}, 54.7 \pm 4.3 \mathrm{~mm}$ and $50.7 \pm 3.9 \mathrm{~mm}$ respectively. The average tibial aspect ratio was $1.51 \pm$ 0.07. Males had larger values of tML, tLAP, tMAP, tCAP, tAP as compared to females $(\mathrm{p}<0.01)$. A positive correlation was observed between tAP and tML for both the genders (Figure 2(b)). In case of the tibial aspect ratio (tR), no statistically significant difference was found between males and females $(\mathrm{p}=0.152)$.

\subsection{Comparison with Other Ethnic Groups}

To compare the Indian knees morphologically with other ethnic groups, the anthropometric measurements of knees various ethnicities were retrieved from literature. The aspect ratios were defined as mentioned above in order to make our data coherent with the anthropometric data of other ethnic groups. The data of the distal femur of Indian population was compared with that of Chinese, Caucasian and American population [5,12] as shown in Table 3. The data of the proximal tibia of the Indian population was compared to that of Chinese, Korean and 


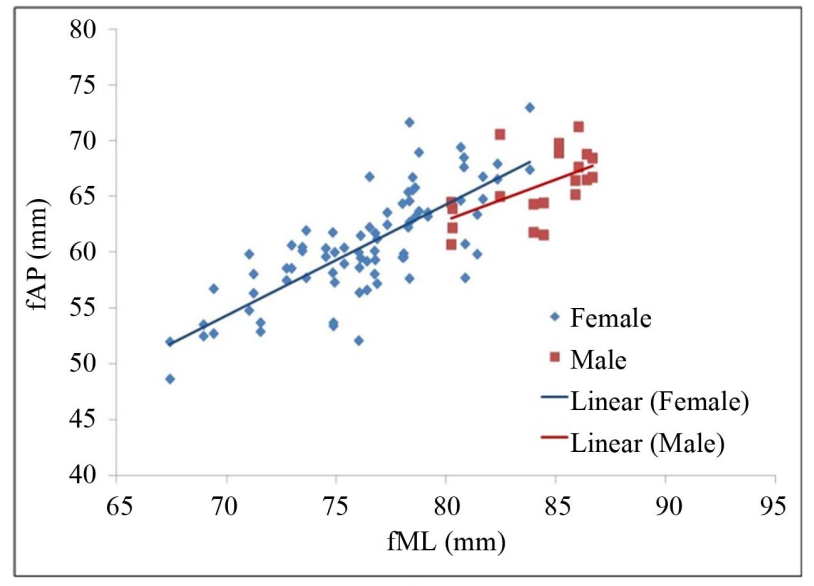

(a)

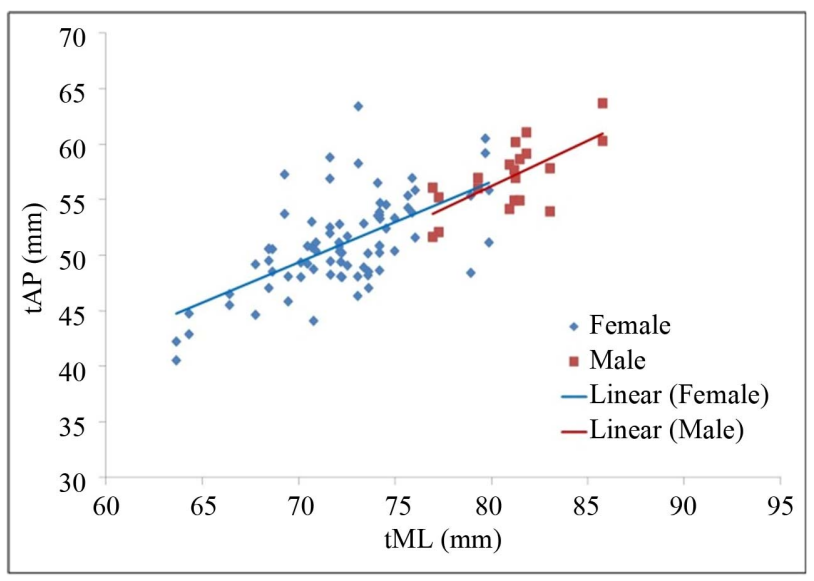

(b)

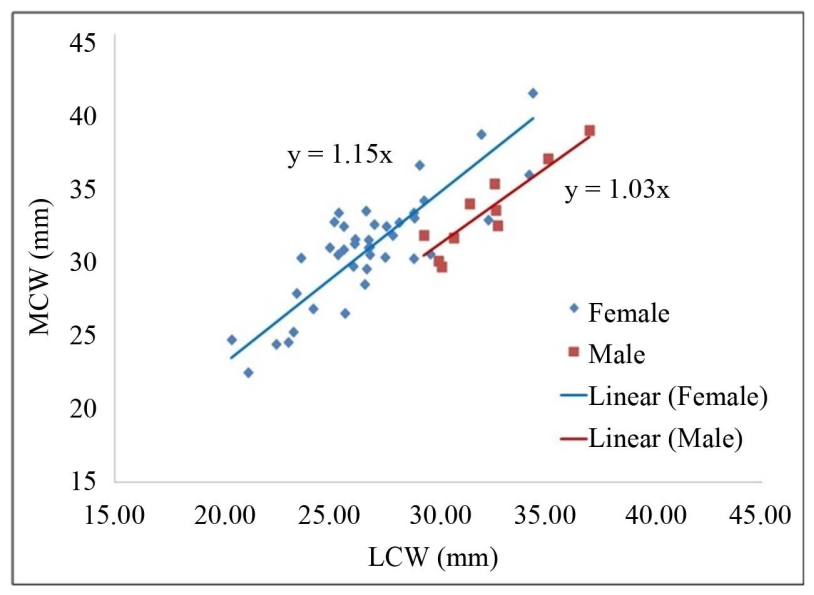

(c)

Figure 2. Genderwise comparison of Indian population; (a) Femoral dimensions (b) Tibial dimensions (c) Femoral condylar widths.

American population [7,13,14] as shown in Table 4.

In case of male femur, Indians had a smaller fML than the Caucasians and Americans but similar to the Chinese. Since fAP was similar for all the ethnicities, fR showed a
Table 2. Summary of tibial measurements_-Indian knees.

\begin{tabular}{ccccc}
\hline Parameters & Combined & Male & Female & $\mathbf{p}^{\mathbf{a}}$ \\
\hline $\begin{array}{c}\text { Mediolateral (tML) } \\
\text { Medial Antero-Posterior } \\
\text { (tMAP) }\end{array}$ & $76.6 \pm 4.9$ & $80.9 \pm 2.6$ & $72.2 \pm 3.6$ & $<0.01$ \\
$\begin{array}{c}\text { Lateral Antero-Posterior } \\
\text { (tLAP) }\end{array}$ & $54.7 \pm 4.3$ & $57.7 \pm 1.9$ & $51.6 \pm 3.9$ & $<0.01$ \\
$\begin{array}{c}\text { Central Antero-Posterior } \\
\text { (tCAP) }\end{array}$ & $50.7 \pm 3.9$ & $53.5 \pm 2.7$ & $47.9 \pm 3.3$ & $<0.01$ \\
$\begin{array}{c}\text { Anteroposterior (tAP) } \\
\text { Aspect Ratio (tR) }\end{array}$ & $55.4 \pm 4.6$ & $58.5 \pm 2.5$ & $52.2 \pm 4.2$ & $<0.01$ \\
\hline
\end{tabular}

${ }^{\mathrm{a}}$ The p-values are calculated for comparison across genders.

Table 3. Summary of femoral measurements-various ethnicities.

\begin{tabular}{|c|c|c|c|c|c|}
\hline Authors & Ethnicity & No & fML & fAP & fR \\
\hline \multicolumn{6}{|c|}{ Males } \\
\hline Our study & Indian & 10 & $83.6 \pm 2.6$ & $67.2 \pm 2.9$ & $1.25 \pm 0.05$ \\
\hline Yue et al. & Chinese & 20 & $\begin{array}{c}82.6 \pm 3.6 \\
(0.393)^{\mathrm{a}}\end{array}$ & $\begin{array}{c}65.0 \pm 2.8 \\
(0.064)\end{array}$ & $\begin{array}{c}1.27 \pm 0.03 \\
(0.267)\end{array}$ \\
\hline Yue et al. & Caucasian & 20 & $\begin{array}{c}86.0 \pm 5.6 \\
(0.120)\end{array}$ & $\begin{array}{c}67.5 \pm 3.6 \\
(0.808)\end{array}$ & $\begin{array}{c}1.28 \pm 0.07 \\
(0.190)\end{array}$ \\
\hline Berger et al. & American & 75 & $\begin{array}{c}85.6 \pm 5.1 \\
(0.062)\end{array}$ & $\begin{array}{c}68.1 \pm 4.6 \\
(0.409)\end{array}$ & -- \\
\hline \multicolumn{6}{|c|}{ Females } \\
\hline Our Study & Indian & 40 & $76.3 \pm 3.8$ & $61.3 \pm 4.6$ & $1.23 \pm 0.06$ \\
\hline Yue et al. & Chinese & 20 & $\begin{array}{c}72.8 \pm 2.6 \\
(<0.001)\end{array}$ & $\begin{array}{c}58.8 \pm 2.5 \\
(0.009)\end{array}$ & $\begin{array}{c}1.24 \pm 0.04 \\
(0.446)\end{array}$ \\
\hline Yue et al. & Caucasian & 16 & $\begin{array}{c}76.4 \pm 4.0 \\
(0.932)\end{array}$ & $\begin{array}{c}59.7 \pm 2.6 \\
(0.107)\end{array}$ & $\begin{array}{c}1.28 \pm 0.06 \\
(0.009)\end{array}$ \\
\hline Berger et al. & American & 75 & $\begin{array}{c}75.4 \pm 2.3 \\
(0.176)\end{array}$ & $\begin{array}{c}60.2 \pm 2.0 \\
(0.156)\end{array}$ & -- \\
\hline
\end{tabular}

${ }^{\mathrm{a}}$ The p-values reported in parenthesis are calculated for comparisons of each ethnic group to the Indian populations.

similar trend as fML across ethnicities. However, since sample size for femur of males of different populations was very low, the above observations were not statistically significant ( $p>0.05)$. In case of female femur, Indians had a larger fML and fAP than the Chinese $(\mathrm{p}<$ $0.01)$. However, Indians had a smaller $f R$ than Caucasians $(p=0.009)$ but similar to Chinese. Another study by Poilvache et al. [15] reported the femoral aspect ratio as 1.33 for white males and 1.29 for white females. Comparing this data with that of Indians, we find that Indians have a smaller $\mathrm{fR}$ than Americans.

In case of male tibia, Indians had a larger tML and tCAP than the Chinese and Koreans ( $\mathrm{p}<0.04)$. However, Indians had a smaller tR than Americans but similar to Chinese. The statistical significance could not be calcu- 
Table 4. Summary of tibial measurements—various ethnicities.

\begin{tabular}{|c|c|c|c|c|c|}
\hline Authors & Ethnicity & No & tML & tCAP & tR \\
\hline \multicolumn{6}{|c|}{ Males } \\
\hline Our study & Indian & 10 & $80.9 \pm 2.6$ & $53.5 \pm 2.7$ & $1.51 \pm 0.05$ \\
\hline Cheng et al. & Chinese & 94 & $\begin{array}{c}76.4 \pm 2.8 \\
(<0.001)\end{array}$ & $\begin{array}{c}51.3 \pm 2.0 \\
(0.031)^{\mathrm{a}}\end{array}$ & $\begin{array}{c}1.49 \pm 0.06 \\
(0.263)\end{array}$ \\
\hline Kwak et al. & Korean & 100 & $\begin{array}{c}76.1 \pm 4.0 \\
(<0.001)\end{array}$ & $\begin{array}{c}48.2 \pm 3.3 \\
(<0.001)\end{array}$ & 1.58 \\
\hline Mensch et al. & American & 30 & $\begin{array}{c}80.3 \pm 3.7 \\
(0.578)\end{array}$ & $\begin{array}{c}48.9 \pm 2.3 \\
(<0.001)\end{array}$ & -- \\
\hline \multicolumn{6}{|c|}{ Females } \\
\hline Our study & Indian & 40 & $72.2 \pm 3.6$ & $47.9 \pm 3.3$ & $1.51 \pm 0.08$ \\
\hline Cheng et al. & Chinese & 78 & $\begin{array}{c}68.8 \pm 4.6 \\
(<0.001)\end{array}$ & $\begin{array}{c}45.7 \pm 1.9 \\
(<0.001)\end{array}$ & $\begin{array}{c}1.51 \pm 0.06 \\
(0.168)\end{array}$ \\
\hline Kwak et al. & Korean & 100 & $\begin{array}{c}67.6 \pm 3.1 \\
(<0.001)\end{array}$ & $\begin{array}{c}43.2 \pm 2.3 \\
(<0.001)\end{array}$ & 1.56 \\
\hline Mensch et al. & American & 30 & $\begin{array}{c}70.1 \pm 2.8 \\
(0.008)\end{array}$ & $\begin{array}{c}42.1 \pm 1.7 \\
(<0.001)\end{array}$ & -- \\
\hline
\end{tabular}

lated due to unavailability of data. In case of female tibia, Indians had a larger tML and tCAP than Chinese, Korean and American population $(\mathrm{p}<0.001)$. However, Indians had a smaller tR than Americans but similar to Chinese. The statistical significance could not be calculated due to unavailability of data.

\subsection{Comparison with Existing Western Implant}

In preoperative implantation, the mediolateral distance, parallel to transepicondylar axis on the distal cut plane of the resected bone, was $63.37 \mathrm{~mm}$ (Figure 3). A femoral component (size 3) of ML $=64 \mathrm{~mm}$ and $\mathrm{fAP}=56 \mathrm{~mm}$ was selected according to the implant selection guide of the implant manufacturer. The posterior resection of the lateral and medial condyle is shown in Figure 4(a). The lateral condyle was observed to be partially resected. Furthermore, the virtual implantation showed overhang of the femoral component in both lateral and medial regions of the anterior surface (Figures 4(b) and (c)). Similarly, overhang was also observed in the lateral condyle (Figure 4(d)). The virtual implantation of the next available smaller size, with femoral component (size 2) of $\mathrm{fML}=63 \mathrm{~mm}$ and $\mathrm{fAP}=51 \mathrm{~mm}$ was carried out. The posterior resection of the lateral and medial condyle for this component is shown in Figure 5(a). The virtual implantation showed overhang of the implant in lateral and medial regions of anterior and lateral condyle (Figures 5(b)-(d)).

\section{Discussion}

A precise surgical procedure like total knee replacement

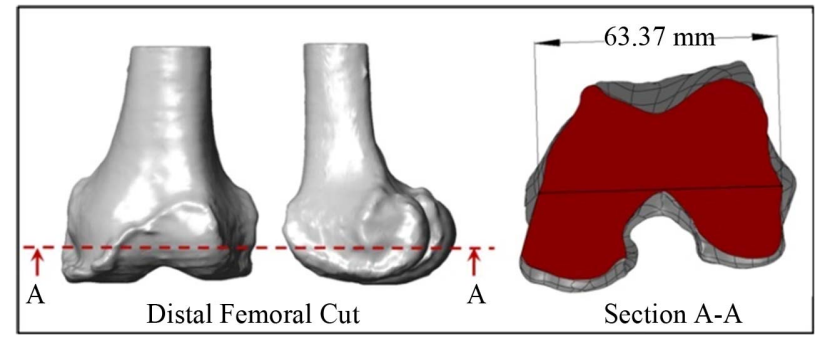

Figure 3. Resection of distal femur of an Indian patient for a Western implant.

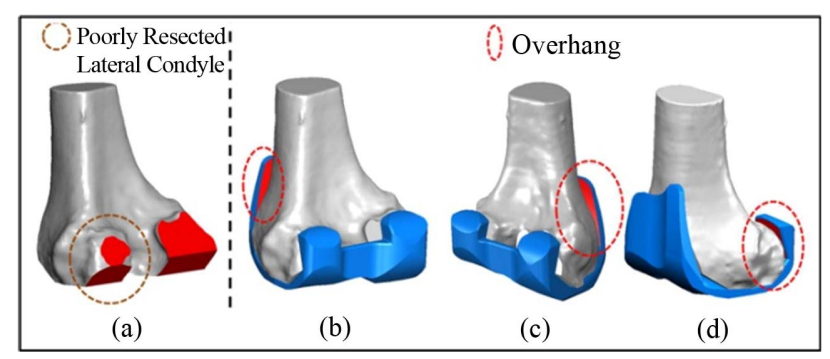

Figure 4. Virtual implantation of Western implant of size 3 (a) Resection of Indian femur (b) Anterolateral overhang (c) Anteromedial overhang (d) Lateral condyle overhang.

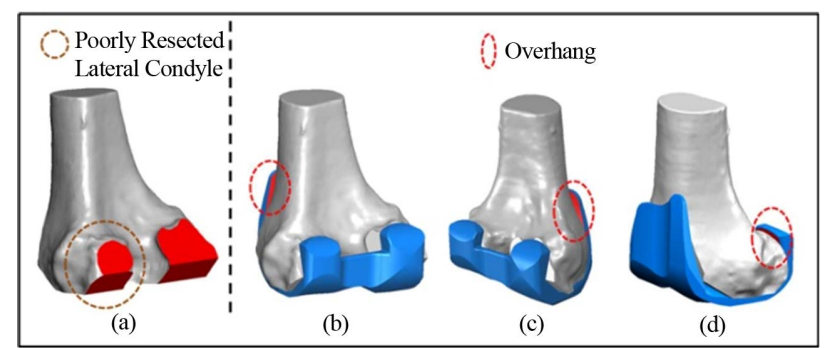

Figure 5. Virtual implantation of Western implant of size 2 (a) Resection of Indian femur (b) Anterolateral overhang (c) Anteromedial overhang (d) Lateral condyle overhang.

requires an almost perfect shape match between the prosthesis and the resected surface of the knee for long-term success [2]. Asian knees are found to be generally smaller than the Western population as suggested by various studies [3-5,9]. Since maximum resected surface of the knee has to be covered by the components of the knee implants [2,9], it is important to know the morphology of the Indian knees to design or validate knee prostheses for the Indian population. The 3D CT image of the knee can undergo unconstrained rotation and the correct three dimensional axis can be determined and maintained [16]. Since measurements from the CT images strongly correlate to intraoperative measurements, this study used a 3D CT imaging technique for morphological measurements on the Indian femur and tibia.

In case of the Indian population, male dimensions were found to be greater than female dimensions in all measured aspects of both the femur and tibia. This trend was 
observed in other ethnic groups too and this study showed a conformation with this general trend. However, the femoral and tibial aspect ratio did not vary with the gender in the measured Indian population. The femoral and tibial aspect ratio of the studied Indian knees was found to be similar to Chinese population rather than the Western population. However, it should be stated that our data was measured from intact knee models whereas some data, retrieved from literature, was measured after bone cutting in TKA.

A novel set of measurements, not to be found anywhere in the previous literature, was performed on the distal femur of the Indian population. The width of the medial and lateral femoral condyles was measured. In case of Indian females, the medial condyle was statistically wider than the lateral condyle while in case of Indian males, both the condylar widths were similar. This observation supports the claim that a gender-specific TKA implant is necessary for the Indian population.

The virtual 3D implantation could provide effective preoperative surgery planning and implant selection. Since, overhang of an implant component is always undesirable, frequent overhangs of the femoral component on the Indian knee questioned the anatomical suitability of Western implants for the Indian population. As observed in the above mentioned case, the recommended implant (size 2,3) was seen to have overhangs which meant that the surgeon would have to choose an implant of even smaller size (size 1). This compromise of selection would result in additional resection of the bone leading to an undesirable loss of healthy bone. Moreover, decreasing the size of the implant, and hence the radius of curvature during knee flexion-extension, would affect the biomechanics of the replaced knee.

This study may provide the directions for designing better TKA implants, especially gender-specific designs, more suitable to people in the Indian sub-continent. This will enhance the anatomical conformity of implants for the patients, leading to better biomechanics and gait.

One of the limitations of this study was the relatively small sample size. Larger sample size of male femur and tibia measurements would reinforce the statistical significance of comparison between Indian population and other ethnic groups. Another limitation of this analysis was the lack of morphologic data of healthy, non-arthritic knees. In this study, we chose osteoarthritic knees to study and compare the morphology of Indian knee with other ethnicities and foreign implants. However, for the Indian population, whether prosthesis should be designed according to the normal or osteoarthritic knee morphology needs further research.

\section{Conclusion}

In our study, we obtained anthropometric data of the In- dian population and compared it with other ethnic groups. Overall morphology of the studied Indian population conforms to other Asian ethnic groups and differs from the Western population. Male dimensions are greater than female dimensions in all measured aspects of the femur and tibia for the Indian population; however, femoral and tibial aspect ratio does not vary with the gender. Only in case of Indian females, the medial condylar width is greater than the lateral condylar width. Anatomic suitability of Western implants on Indian population is still questionable.

\section{Acknowledgements}

This work has been carried out at the OrthoCAD Lab set up with funding by the Office of the Principal Scientific Advisor to the Government of India, New Delhi. The extensive support, including CT imaging and data provided by the Department of Orthopaedics at Hiranandani Hospital, Mumbai is gratefully acknowledged.

\section{REFERENCES}

[1] S. J. Incavo, P. J. Ronchetti, J. G. Howe and J. P. Tranowski, "Tibial Plateau Coverage in Total Knee Arthroplasty,” Clinical Orthopaedics, Vol. 299, 1994, pp. 81-85.

[2] C. K. Cheng, C. Y. Lung, Y. M. Lee and C. H. Huang, “A New Approach of Designing the Tibial Base Plate of Total Knee Prostheses," Clinical Biomechanics, Vol. 14, No. 2, 1999, pp. 112-117. http://dx.doi.org/10.1016/S0268-0033(98)00054-0

[3] W. P. Ho, C. K. Cheng and J. J. Liau, "Morphometrical Measurements of Resected Surface of Femurs in Chinese Knees: Correlation to the Sizing of Current Femoral Implants,” Knee, Vol. 13, No. 1, 2006, pp. 12-14. http://dx.doi.org/10.1016/j.knee.2005.05.002

[4] K. Urabe, H. Miura, T. Kuwano, et al., "Comparison between the Shape of Resected Femoral Sections and Femoral Prostheses Used in Total Knee Arthroplasty in Japanese Patients: Simulation Using Three-Dimensional Computed Tomography," The Journal of Knee Surgery, Vol. 16, No. 1, 2003, pp. 27-33.

[5] S. V. Vaidya, C. S. Ranawat, A. Aroojis and N. S. Laud, "Anthropometric Measurements to Design Total Knee Pro-stheses for the Indian Population,” The Journal of Arthroplasty, Vol. 15, No. 1, 2000, pp. 79-85. http://dx.doi.org/10.1016/S0883-5403(00)91285-3

[6] G. H. Westrich, S. B. Haas and J. N. Insall, "Resection Specimen Analysis of Proximal Tibial Anatomy Based on 100 Total Knee Arthroplasty Specimens," The Journal of Arthroplasty, Vol. 10, No. 1, 1995, pp. 47-51.

[7] K. Uehara, Y. Kadoya, A. Kobayashi, H. Ohashi and Y. Yamano, "Anthropometry of the Proximal Tibia to Design a Total Knee Prosthesis for the Japanese Population,” The Journal of Arthroplasty, Vol. 17, No. 8, 2002, pp. 10281032. http://dx.doi.org/10.1054/arth.2002.35790

[8] H. A. Kim, S. Kim, Y. I. Seo, et al., "The Epidemiology 
of Total Knee Replacement in South Korea: National Registry Data,” Rheumatology Oxford, Vol. 47, No. 1, 2008, p. 88. http://dx.doi.org/10.1093/rheumatology/kem308

[9] D. S. Kwak, S. Sibin, G. Patinharayil, et al., "Morphometry of the Proximal Tibia to Design the Tibial Component of Total Knee Arthroplasty for the Korean Population," Knee, Vol. 14, No. 4, 2007, pp. 295-300. http://dx.doi.org/10.1016/j.knee.2007.05.004

[10] B. Yue, M. V. Kartik, A. Songtao, T. Tingting, E. R. Harry and L. Guoan, "Differences of Knee Anthropometry between Chinese and White Men and Women," The Journal of Arthroplasty, Vol. 26, No. 1, 2011, pp. 124-130. http://dx.doi.org/10.1016/j.arth.2009.11.020

[11] M. P. Bonnin, S. Mohammed, P. E. Mercier, J. R. Laurent and C. Yannick, "Is the Anterior Tibial Tuberosity a Reliable Rotational Landmark for the Tibial Component in Total Knee Arthroplasy?” The Journal of Arthroplasty, Vol. 26, No. 2, 2011, pp. 260-267. http://dx.doi.org/10.1016/j.arth.2010.03.015

[12] R. A. Berger, H. E. Rubash, M. J. Seel, W. H. Thompson and L. S. Crossett, "Determining the Rotational Alignment of the Femoral Component in Total Knee Arthroplasty Using the Epicondylar Axis,” Clinical Orthopaedics and Related Research, Vol. 286, 1993, pp. 40-47.

[13] F. B. Cheng, X. F. Ji, Y. Lai, et al., "Three Dimensional Morphometry of the Knee to Design the Total Knee Arthroplasty for Chinese Population,” Knee, Vol. 16, No. 5, 2009, pp. 341-347. http://dx.doi.org/10.1016/j.knee.2008.12.019

[14] J. Mensch and H. Amstutz, "Knee Morphology as a Guide to Knee Replacement," Clinical Orthopaedics and Related Research, Vol. 112, 1975, pp. 231-241.

[15] P. L. Poilvache, J. N. Insall, G. R. Scuderi, et al., "Rotational Landmarks and Sizing of the Distal Femur in Total Knee Arthroplasty," Clinical Orthopaedics and Related Research, Vol. 331, 1996, pp. 35-46.

[16] I. S. Lee, J. A. Choi, T. K. Kim, I. Han, J. W. Lee and H. S. Kang, "Reliability Analysis of 16-MDCT in Preoperative Evaluation of Total Knee Arthroplasty and Comparison with Intraoperative Measurements," American Journal of Roentgenology, Vol. 186, No. 6, 2006, pp. 17781782. http://dx.doi.org/10.2214/AJR.05.1191 